\title{
Protocol
}

\section{Randomized controlled trial of an E-learning program for physiotherapy students to improve the management of rotator cuff related shoulder pain: a study protocol}

\author{
Bahar Ayberk*, Mine Gülden Polat
}

Department of Physiotherapy and Rehabilitation, Marmara University, İstanbul, Turkey

Received: 02 October 2021

Accepted: 09 December 2021

*Correspondence:

Bahar Ayberk,

E-mail: bhargnes@gmail.com

Copyright: (C) the author(s), publisher and licensee Medip Academy. This is an open-access article distributed under the terms of the Creative Commons Attribution Non-Commercial License, which permits unrestricted non-commercial use, distribution, and reproduction in any medium, provided the original work is properly cited.

\section{ABSTRACT}

Background: The majority of shoulder complaints are occurred due to rotator cuff pathologies. Although conservative treatments including physiotherapy are acknowledged as the first-line treatment approach in the management of shoulder pain, the uptake of physiotherapy practice is variable. One possible explanation of this could be the poor evidence-based knowledge mobilization to practice. The aim of the study was to evaluate the efficacy of an E-learning program on physiotherapy students' knowledge of evidence-based Rotator cuff-related shoulder pain (RCRSP) management and their confidence in applying this care compared to a control group.

Methods: A randomized controlled study will be carried with 146 fourth-year physiotherapy students. Students will be assigned to one of two groups: E-learning $(\mathrm{N}=73)$ or control $(\mathrm{N}=73)$. The outcomes will be: (1) RCRSP knowledge and clinical reasoning skills, and (2) self-reported confidence in RCRSP knowledge and clinical reasoning abilities. Both measurements will be held at baseline and post-intervention.

Conclusions: This is the first trial to investigate if a specifically designed E-learning program besides a regular learning curriculum, improves students' knowledge and self-confidence in the RCRSP management. Enhancing students' aftergraduation readiness to manage patients with RCRSP may help to allow patients access to evidence-informed physiotherapists.

Trial registration: This trial was registered on clinicalTrials.gov on 17 June 2021 (NCT04952623)

Keywords: E-learning, Rotator cuff injuries, Physiotherapy education

\section{INTRODUCTION}

The Rotator cuff-related pathologies (RCRSP) constitute $70 \%$ of shoulder pain complaints. ${ }^{1}$ Shoulder pain is not a short-lasting problem for the majority of patients. Shoulder pain and functional difficulties following rotator cuffrelated pathology severely interfere with daily life activities. Forty percent of the patients complain of recurrent symptoms within 12 months from the onset of the disease. ${ }^{2}$ Moreover, poor long-term outcomes cause the majority of patients to seek more invasive and expensive treatment options such as injections or surgery. ${ }^{3}$ Conservative therapies, such as physiotherapy and rehabilitation, are often considered as the first-line treatment strategy for shoulder pain, however, there is considerable variation in physiotherapy practice. ${ }^{4,5}$ According to studies on physiotherapists' preferences about the care of RCRSP, clinicians tend to prefer passive treatment modalities as well as evidence-based treatment strategies. $^{6}$

Researchers also emphasized that there still is a gap between literature evidence and physiotherapy practice which is due to the lack of effective knowledge mobilization. ${ }^{6}$ Therefore, the ineffectual knowledge mobilization reveals the importance of alternative learning 
methods such as E-learning programs to be designed to increase physiotherapy students' knowledge and management skills about RCRSP.

The delivery of education by using electronic technologies is known as E-learning. ${ }^{7}$ E-learning is an advantageous way of learning because it is low-cost, highly accessible, and allows personalized content and learning speed. ${ }^{8}$ In addition, E-learning adapts adult learning paradigms because of its' interactivity and combinability with the other learning models. ${ }^{9}$ Moreover, E-learning programs are alternative learning methods to improve healthcare professionals' evidence-based knowledge and practice and have been widely studied in the literature. ${ }^{10-14}$ The effects of E-learning interventions on physiotherapists' and physiotherapy students' knowledge on different pathologies such as rheumatoid arthritis, spinal cord, and fall rehabilitation have been documented before. ${ }^{12,13,15,16}$ On the other hand, there is a limitation of evidence about the effects of an E-learning program on the knowledge of physiotherapy students concerning shoulder pain. As a result, the purpose of this research is to evaluate the effect of participating in an RCRSP E-learning program on physiotherapy students' knowledge of evidence-based RCRSP management and their levels of confidence in implementing this knowledge, compared with the control group.

\section{METHODS}

\section{Trial design}

Consolidated Standards of Reporting Trials (CONSORT) statement will be followed to execute the randomized controlled trial (Figure 1). ${ }^{17}$ Standard Protocol Items: Recommendations for Interventional Trials (SPIRIT) statement will be used to construct and present the study protocol. ${ }^{18}$ Educational content was outlined by following the template for intervention description and replication checklist. ${ }^{19}$

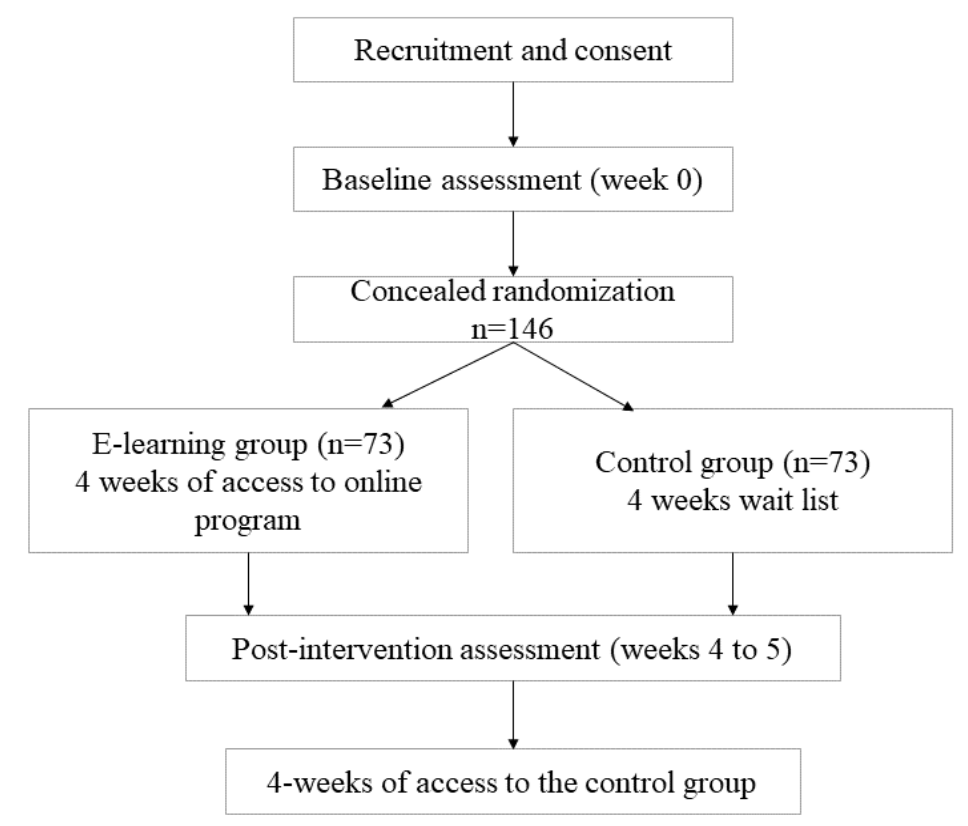

Figure 1: Trial design.

\section{Recruitment}

One hundred forty-six students will be recruited through advertising posted on social media via physiotherapy student clubs or in the newsletters of Turkish Physiotherapy Associations.

The recruitment advertisements will include information about the study and a consent link if the student demands to participate. The students who give consent to participate will be contacted by a researcher and informed about the further steps of the study.

The recruitment process will begin in February 2022.

\section{Eligibility criteria}

Participants must be fourth-year undergraduate physiotherapy students to be eligible for the study.

The students who are not enrolled in fourth grade will be excluded.

\section{Randomization}

To ensure allocation concealment, randomization will be administered by a researcher who is not engaged in recruiting or reporting process. Participants will randomly be assigned to one of two groups: E-learning or control. To 
maintain intergroup balance, a computer-generated random number sequence will be utilized.

\section{Intervention}

The RCRSP E-learning program is a self-paced online training created by the research group based on current evidence-based research. ${ }^{20-23}$ The E-learning program was prepared using the ADDIE Instructional design model. ${ }^{24}$ The program comprises a brief introduction followed by three modules that cover RCRSP definition, symptoms, evaluation and diagnosis, and comprehensive RCRSP management (Table 1).

Table 1: The description of intervention in accordance with the Temple for Intervention Description and Replication (TIDieR) checklist.

\begin{tabular}{|c|c|}
\hline Name & $\begin{array}{l}\text { E-learning program for } \\
\text { physiotherapy students on Rotator } \\
\text { cuff-related shoulder pain } \\
\text { (RCRSP). }\end{array}$ \\
\hline Why & $\begin{array}{l}\text { E-learning interventions have been } \\
\text { shown to be as beneficial as } \\
\text { traditional learning interventions, } \\
\text { with the added advantages of being } \\
\text { more accessible and user-friendly } \\
\text { (Wentling, 2000). }\end{array}$ \\
\hline $\begin{array}{l}\text { What } \\
\text { materials }\end{array}$ & $\begin{array}{l}\text { The E-learning program consists of } \\
\text { texts, infographics, and instructional } \\
\text { videos. }\end{array}$ \\
\hline $\begin{array}{l}\text { What } \\
\text { procedures }\end{array}$ & $\begin{array}{l}\text { The E-learning program has three } \\
\text { modules as outlined below: } \\
\text { Module 1: Introduction } \\
\text {-Understanding RCRSP } \\
\text { Module 2: Assessment } \\
\text {-Physiotherapy assessment } \\
\text {-Literature evidence about special } \\
\text { orthopedic tests and imaging methods } \\
\text {-Shoulder symptom modification } \\
\text { procedure } \\
\text { Module 3: Treatment } \\
\text {-Patient education } \\
\text {-Exercise } \\
\text {-Other treatment methods }\end{array}$ \\
\hline $\begin{array}{l}\text { Who } \\
\text { provided }\end{array}$ & $\begin{array}{l}\text { The E-learning program has been } \\
\text { designed and developed by the } \\
\text { authors according to the ADDIE } \\
\text { Instructional Design Model } \\
\text { (Muruganantham, 2015). }\end{array}$ \\
\hline How & $\begin{array}{l}\text { The E-learning program is an } \\
\text { individually delivered self-paced } \\
\text { online activity. }\end{array}$ \\
\hline Where & $\begin{array}{l}\text { Students access the online content } \\
\text { through www.rmftr.com website. }\end{array}$ \\
\hline $\begin{array}{l}\text { When and } \\
\text { how much }\end{array}$ & $\begin{array}{l}\text { Each student will have four weeks to } \\
\text { complete the E-learning program. }\end{array}$ \\
\hline Tailoring & $\begin{array}{l}\text { The online content will be the same } \\
\text { for all participants. }\end{array}$ \\
\hline
\end{tabular}

\section{Outcomes}

The outcome measures will be collected from participants by completing the RCRSP achievement test and selfreported confidence in knowledge related to RCRSP at two-time points. The outcome measures will be completed by both groups at baseline (week 0) and post-intervention (weeks 4-5). To avoid contamination, the correct answers to the outcome measure (RCRSP achievement test) are not given and hence cannot be shared among participants. Furthermore, a demographic information survey will be applied at baseline.

\section{Randomized controlled trial}

The outcome measures will be: (a) RCRSP achievement test: The test was designed by the authors according to current literature. ${ }^{20-23}$ The aim of the test was to measure the participants' knowledge about rotator cuff anatomy and kinesiology, rotator cuff tendinopathy mechanism, RCRSP symptoms, RCRSP management strategies, and interventions. The test consists of 18 multiple-choice questions. The Kuder Richardson 20 reliability coefficient of the test is 0.84 . In addition, the average difficulty of the test is moderate $(0.59)$ and its distinctiveness is very good (0.52). Therefore, the RCRSP achievement test is a reliable and valid measurement tool; and (b) self-reported confidence in RCRSP-related knowledge and clinical skills: The researchers used a 5-point Likert scale to create this questionnaire. The questionnaire includes three items. Participants will be asked to score their self-confidence to practice evidence-based intervention based on their knowledge and clinical abilities.

\section{Control group}

The control group will access the E-learning program 4-5 weeks after the baseline assessment measures are completed.

\section{Sample size considerations}

With an $80 \%$ power and a two-tailed of 0.05 , a total sample of 112 students is necessary to achieve a moderate effect size $(\mathrm{d}=0.5)$ of an increase in clinical knowledge of evidence-based RCRSP care. We intend to recruit 146 individuals with an assumption of a potential $30 \%$ dropout rate. Estimates of the dropout rate and effect size were determined in accordance with the previous similar research. $^{12}$

\section{Analysis of outcomes}

The inter-group differences at baseline will be analyzed by using an independent t-test for the achievement test and Mann-Whitney $U$ tests for the self-reported confidence questionnaire. To specify if the E-learning group improves in knowledge and confidence related to RCRSP compared to the control group, an intention-to-treat analysis will be used. To determine the change of scores from the baseline 
to post-intervention between groups, an independent t-test will be used for the achievement test and the MannWhitney $U$ test will be used for measuring the confidence of the participants. All statistical analyses will be conducted by using SPSS software and the researcher who is responsible for data analysis will be blinded to group allocation.

\section{DISCUSSION}

Given the nature of shoulder pain and its negative consequences on patients' everyday lives, and despite physiotherapy is one of the first-line treatment methods, the practice preferences of physiotherapists are variable. There is a lack of learning methods to knowledge mobilization between the literature and practice. As far as we know, no research has been carried to demonstrate the efficacy of an E-learning program on physiotherapy students' knowledge and clinical skills related to RCRSP management. This trial aims to investigate if a specifically designed E-learning program besides a regular learning curriculum, improves students' knowledge and selfconfidence in the care of patients with RCRSP.

The learning analytics of this trial could allow to identify the students' background knowledge level about RCRSP and to make inferences about the existing curriculum.

\section{CONCLUSION}

Enhancing students' after-graduation readiness to manage patients with RCRSP may help to allow patients access to evidence-informed physiotherapists. Increasing students' skills before graduation could cause an opportunity to increase workforce capacity in primary care.

Funding: No funding sources

Conflict of interest: None declared

Ethical approval: The permission was obtained from Marmara University Ethics Committee (Protocol number:16.11.2020-95)

\section{REFERENCES}

1. Windt DA, Koes BW, Jong BA, Bouter LM. Shoulder disorders in general practice: incidence, patient characteristics, and management. Ann Rheum Dis. 1995;54(12):959-64.

2. Kooijman M, Swinkels I, Dijk C, Bakker D, Veenhof C. Patients with shoulder syndromes in general and physiotherapy practice: an observational study. BMC Musculoskelet Disord. 2013;14:128.

3. Winters JC, Sobel JS, Groenier KH, Arendzen JH, Jong B. The long-term course of shoulder complaints: a prospective study in general practice. Rheumatology. 1999;38(2):160-3.

4. Dorrestijn O, Stevens M, Winters JC, Meer K, Diercks RL. Conservative or surgical treatment for subacromial impingement syndrome? A systematic review. J Shoulder Elbow Surg. 2009;18(4):652-60.
5. Littlewood C, Malliaras P, Chance-Larsen K. Therapeutic exercise for rotator cuff tendinopathy: a systematic review of contextual factors and prescription parameters. Int $\mathbf{J}$ Rehabil Res. 2015;38(2):95-106.

6. Bury J, Littlewood C. Rotator cuff disorders: a survey of current (2016) UK physiotherapy practice. Shoulder Elbow. 2018;10(1):52-61.

7. Clark RC, Mayer RE. E-Learning and the Science of Instruction: Proven Guidelines for Consumers and Designers of Multimedia Learning. 3rd ed. San Fransisco, CA: Pfeiffer; 2011.

8. Wentling TL, Waight C, Gallagher J, Fleur J, Wang C, Kanfer A. E-learning- A review of literature. USA: University of Illinois at Urbana-Champaign; 2000: 13-34.

9. Gibbons A, Fairweather P. Computer-based instruction. In: Tobias S, Fletcher J, eds. Training \& Retraining: A Handbook for Business, Industry, Government, and the Military. New York, NY: Macmillan Reference USA; 2000: 43-114.

10. Cobb SC. Internet continuing education for health care professionals: an integrative review. J Contin Educ Health Prof. 2004;24(3):171-80.

11. Cook DA, Levinson AJ, Garside S, Dupras DM, Erwin PJ, Montori VM. Internet-based learning in the health professions: a meta-analysis. JAMA. 2008;300(10):1181-96.

12. Fary RE, Slater H, Chua J, Ranelli S, Chan M, Briggs AM. Policy-into-practice for rheumatoid arthritis: randomized controlled trial and cohort study of elearning targeting improved physiotherapy management. Arthritis Care Res (Hoboken). 2015;67(7):913-22.

13. Harvey LA, Glinsky JV, Lowe R, Lowe T. A massive open online course for teaching physiotherapy students and physiotherapists about spinal cord injuries. Spinal Cord. 2014;52(12):911-8.

14. Li SH, Sandler CX, Casson SM, Cassar J, Bogg T, Lloyd AR, et al. Randomised controlled trial of online continuing education for health professionals to improve the management of chronic fatigue syndrome: a study protocol. BMJ Open. 2017;7(5):14133.

15. Tiedemann A, Sturnieks DL, Hill AM, Lovitt L, Clemson L, Lord SR, et al. Does a fall prevention educational programme improve knowledge and change exercise prescribing behaviour in health and exercise professionals? A study protocol for a randomised controlled trial. BMJ Open. 2014;4(11):007032.

16. Fary RE, Slater H, Gardner P, Jordan JE, Chua J, Briggs AM. Embedding digital rheumatoid arthritis education into physiotherapy curriculum to increase workforce readiness of new graduates: a mixed methods study. Physiotherapy. 2015;101:376.

17. Schulz KF, Altman DG, Moher D, CONSORT Group. CONSORT 2010 Statement: updated guidelines for reporting parallel group randomised trials. BMC Med. 2010;8:18. 
18. Chan AW, Tetzlaff JM, Gøtzsche PC, Altman DG, Mann H, Berlin JA, et al. SPIRIT 2013 explanation and elaboration: guidance for protocols of clinical trials. BMJ. 2013;346:7586.

19. Hoffmann TC, Glasziou PP, Boutron I, Milne R, Perera R, Moher D, et al. Better reporting of interventions: template for intervention description and replication (TIDieR) checklist and guide. BMJ. 2014;348.

20. Lewis J, McCreesh K, Roy JS, Ginn K. Rotator Cuff Tendinopathy: Navigating the DiagnosisManagement Conundrum. J Orthop Sports Phys Ther. 2015;45(11):923-37.

21. Lewis J. Rotator cuff related shoulder pain: Assessment, management and uncertainties. Man Ther. 2016;23:57-68.
22. Pieters L, Lewis J, Kuppens K, Jochems J, Bruijstens $\mathrm{T}$, Joossens L, et al. An Update of Systematic Reviews Examining the Effectiveness of Conservative Physical Therapy Interventions for Subacromial Shoulder Pain. J Orthop Sports Phys Ther. 2020;50(3):131-41.

23. Salamh P, Lewis J. It Is Time to Put Special Tests for Rotator Cuff-Related Shoulder Pain out to Pasture. J Orthop Sports Phys Ther. 2020;50(5):222-5.

24. Muruganantham G. Developing of E-content package by using ADDIE model. Int J Appl Res. 2015;1(3):52-4.

Cite this article as: Ayberk B, Polat MG. Randomized controlled trial of an E-learning program for physiotherapy students to improve the management of Rotator cuff related shoulder pain: a study protocol. Int J Clin Trials 2022;9(1):29-33. 